\title{
Witnessing distant and proximal suffering within a zone of danger: Lay moralities of media audiences in the Philippines
}

\author{
Jonathan Corpus Ong (jco10@le.ac.uk) \\ University of Leicester, Leicester, UK
}

Reference

Ong, JC. (2015). Witnessing distant and proximal suffering within a zone of danger: Lay moralities of media audiences in the Philippines. International Communication Gazette, 1-16.

\begin{abstract}
Drawing on the anthropology of moralities, the phronetic turn in media ethics scholarship, and audience research in media studies, this article explores how media audiences in the global South are implicated in moral dilemmas of bearing witness. Central are the diverse audience practices of engaging with proximal suffering on one hand and distant suffering on the other, where sympathy with or denial strategies towards suffering others are shaped not only by audiences' geographical distance to tragedy, but crucially by classed moralities that profoundly shape judgments to sufferers and the media that represent them. A synthesis of ethnographic audience research with middleclass and low-income populations in disaster-prone Philippines shows how middle-class moralities of respectability inform social denial to proximal suffering, while low-income people's personal experiences of suffering lead to the instrumenta- lization of television narratives as symbolic resources to cope with their own suffering.
\end{abstract}

Keywords

Classed moralities, distant suffering, disasters and media, lay moralities, media audiences, media witnessing, phronesis, proximal suffering

\section{Introduction}


The mediation of suffering is not only a distant but also a proximal phenomenon and even everyday condition. Drawing from ethnographic research with diverse social groups on their media practices in a developing country with high frequency of natural disasters, I explore how suffering can be simultaneously - and to varying degrees - experienced, witnessed and addressed within everyday contexts of mediation. While the current debate in media ethics remains concerned about the capacities of media to bridge or exacerbate the social divides between the 'zone of safety' in the West and the 'zone of danger' in the global South (Chouliaraki, 2006: 83), we know little about ordinary people in the developing world acting upon images and stories of suffering - their own and those of others. In the literature, there is much critical reflection on distant sufferers in their various guises in the global 'space of appearance' (Silverstone, 2007: 47): as melodramatic figures in humanitarian advertisements (Wells, 2013), as 'dots-on-the-map' in Greek news reports (Chouliaraki, 2006: 137-146), and as the 'starving innocent children' in western photojournalism (Moeller, 2002). At the same time, recent theorizations on 'media witnessing' and new empirical research on suffering situate their analysis of audiences' immediate responses to images of exceptional disaster within the secure setting of western domesticity (Ashuri and Pinchevski, 2009; Scott, 2014).

Drawing on traditions in the anthropology of moralities, the phronetic turn in media ethics scholarship and audience research in media and cultural studies, this article explores how media audiences in the global South are implicated in everyday moral dilemmas of bearing witness: expressing sympathy or indignation toward others' suffering, tuning into or switching off from a media world that reflects back the harsh conditions of one of the most disaster-prone countries in the world, and articulating moral discourses of right and wrong in relation to media conventions of representing suffering (including the suffering they identify as their very own). I call these practices the lay moralities of media audiences, provoked by their everyday encounters with media representations of suffering. This article maps out how lay moralities are expressed in and shaped by the dialectical interplay between media texts of suffering and ordinary people's social positions. The study highlights the salience of class inequalities in the local context of the Philippines as a crucial force in differentiating audience lay moralities of suffering. Following two different ethnographic projects, I discuss how middle-class Filipinos with access to both global discourses of development and aspirational imaginaries of the good life elsewhere, engage with suffering differently from low-income Filipinos who identify as sufferers themselves.

\section{Moralities of the media audience}

Everyday contexts of media engagement are occasions for moral action and reflection, insofar as beliefs and sentiments about the self and one's relationship with distant strangers or proximal vulnerable others are provoked in media reception. This approach is inspired in part by the anthropology of moralities that is concerned with the mapping of moral codes of specific fields or communities. Anthropologists of morality assert that by 
discussing 'morally problematic scenarios' with their subjects, 'unspoken and unconscious moral values' are given voice in conversation and interaction (Heintz, 2009: 12). Therefore, I explore television consumption and reception here as expressive of audiences' lay moralities - for instance, in the diverse ways in which people justify their actions (or non-action) towards mediated sufferers, or make judgments of sufferers deserving of media recognition and public attention.

This approach resonates with the imperatives of neo-Aristotelian phronesis as developed within the media ethics literature. Instead of an ethical analysis premised on the prescription of desirable first principles to guide media and audience practices (e.g. Dayan, 2007; Silverstone, 2007), phronesis identifies the prevailing (as well as competing) moral values in society as instantiated within and called into being by specific acts of public communication. Chouliaraki's work is most instructive for this situated ethics of media, as she analyses different news reports as 'unique enactments of ethical discourse, which, even though it transcends the case, cannot exist except outside the enactment of cases' (2006: 6). In Chouliaraki's approach, media representations are assumed as agentic and performative (2012) in their capacity to circulate value-driven moral proposals for audiences to take up or reject in the face of distant suffering. This article continues on this trajectory by investigating the consumption and reception of news about suffering and the ways in which everyday media practices are revelatory of such moral activities. Following Chouliaraki's phronetic approach and the anthropology of moralities, the everyday consumption and reception of media are fields that unveil and provoke audiences' moral orientations towards vulnerable others in the media, as media practice and talk can incite relationships of care, apathy, or even disgust towards suffering strangers.

In relation to media consumption, there is a normative judgment that audiences should know about the suffering of others. This expectation values everyday acts of television viewing rather than looking away from atrocity (Cohen, 2001; Seu, 2003). Accordingly, previous empirical research on compassion fatigue has studied audience patterns of issue avoidance and information-seeking, as it is assumed that emotionally distressing news 'is more likely to be associated with avoidance behaviours, ostensibly as a form of selfprotection' (Kinnick et al., 1996: 700-701). Likewise, I explore audience patterns of tuning in and switching off from the news within the Philippine media landscape which is rife with images of everyday poverty and natural disaster. Unlike television in other developing contexts such as India which is accused to be in denial of widespread poverty in the country (Sainath, 2009), Philippine television consistently portrays storylines related to poverty. Soap operas typically have a young poor female character as their main protagonist, reality shows have poor elderly housewives as eager participants competing for cash prizes, and news broadcasts cover both momentous events of natural disaster and the everyday problems of slum communities, follow- ing from a 'massoriented' business model that caters to the interests and concerns of two-thirds of the population classified as low-income (Romualdez, 1999: 55). Therefore, this article is 
concerned with how audiences of different social back- grounds may either seek information or actively avoid news about suffering and poverty, made ordinary by conventions of Philippine television.

In relation to media reception, lay moralities are also evident in audiences' immediate responses to specific news texts of suffering. Several scholars underwrite the expressions of effective speech in the face of distant suffering, where emotional responses of compassion and indignation are assumed to reveal ordinary people's relationship of solidarity with vulnerable others (Boltanski, 1999). I therefore approach emotions here as upheavals of thought (Nussbaum, 2001) that reveal cognitive structures and offer insight into processes of moral judgment and the social values that facilitate or disable solidarity with vulnerable others. Of particular interest are people's emotional responses and moral judgments towards competing conventions of representing suffering as either showing 'suffering at its worst', assumed to motivate political action (Orgad, 2008: 21), or showing more positive images of sufferers, assumed to give dignity and agency to the distant others with whom viewers can potentially better identify with (Tester, 2001). So far, the literature has played out this specific debate on the most proper way of representing vulnerable others by using textual critique and the application of normative principles (Silverstone, 2007), with little empirical audience research to explore audiences' lay moralities in the face of competing styles of representation make available (see Ong, 2014a).

Finally, given the context of developing and disaster-prone Philippines as the setting for this study, it is crucial to theorize audiences' witnessing position as one involving not only maximum distance but also varying proximities. Theories of media witnessing so far developed phenomenological accounts of viewing suffering, which assume that images may be 'traumatic in their implications for normal states of awareness' (Ellis, 2009: 85). However, in the case of audiences living within this zone of danger, where disaster is seen as a 'normal way of life' (Bankoff, 2003: 53), viewing suffering may not carry the impact of shock or trauma, but instead serve as an opportunity for personal reflection, catharsis and therapy. In this light, this article seeks to verify and nuance the many assumptions of media audiences' engagement with mediated suffering by taking a dewesternizing and ethnographic approach.

\section{Methodology}

This article draws its synthesis of a sample of audiences' lay moralities in the context of mediated suffering from two different ethnographic research projects.

The first project is a 20-month ethnography conducted intermittently from 2008 to 2010 with television audiences in Manila, Philippines. This ethnography involved spending time in both middle-class neighbourhoods and slum communities and watching and discussing television in 'actually existing' situations to observe both patterns of consumption and reception. The project, which had 92 participants, had a particular focus 
on people's interpretations of factual genres of news, charity appeals and game shows. It also included a series of focus groups to discuss specific texts of distant and proximal suffering (for more information about the project, see Ong, 2015).

The second project is the ongoing collaborative research Humanitarian Technologies Project, which studies the consequences of media and communications technologies to the recovery process of disaster-affected communities from Typhoon Haiyan, which hit central Philippines in November 2013. This project, whose participants include over 100 affected people in Tacloban and Bantayan and 50 experts in the humanitarian, technology and government sectors, primarily explores the various ways in which media technologies can be used for fundraising, giving feedback to humanitarian agencies, and protesting, but additionally inquires about people's perceptions of the narratives produced about them by journalists, humanitarians and the state. This project also has a digital ethnography component, paying attention to various forms of digital storytelling, collective problem- solving and uses for everyday sociality and recreation. Digital ethnography involves the collection of social media data from observing participants' social media accounts and paying attention to trending issues related to the typhoon (see Ong, 2014b).

The discussion in the succeeding sections draws out lay moralities of ordinary people in their consumption and reception of suffering in the news. These lay moralities are articulated in the interaction of texts of distinctive cases of distant or proximal suffering with audiences' social positions and personal experiences. I particularly highlight the role of social class in positioning audiences to sufferers in distinct ways through the value systems that they make available when judging deserving sufferers and evaluating news media's specific techniques of representing suffering. The aim of presenting a sample of lay mor- alities from these two projects is to demonstrate the range of audience engagement with texts of suffering, with an appreciation of the unexpected lay moralities that may arise from the perspective of people in non-western contexts who them- selves are implicated in power asymmetries of mediation and acting on atrocity that is never too far and too strange - but is in fact only too close and too common.

\section{Melodrama and denial in proximal suffering}

It is striking how different audiences demonstrate varying levels of familiarity with news stories and reveal orientations to rather different public worlds. I found that middle-class television audiences consumed more global news and showed high familiarity with international issues while low-income audiences had more intense and affective relationships with local news and also the journalists who report the news from disaster zones and slum areas. This disparity in consumption practices is a matter for ethical critique insofar as audiences reveal different kinds of public connection (Couldry et al., 2007) that in turn position them to be morally culpable for very different groups of sufferers. 
The difference in news consumption could not be fully explained by inequalities in the access and availability of media. All 92 participants - from both the middle-class neighbourhoods and the slum communities - owned a television set which served as their main source of news. Many in the slum communities owned cheap black-and-white sets. Access to cable television and the internet as equally popular news sources was more varied: only a handful of low-income respondents had access to cable channels such as CNN though most of them were able to log on to the internet - used for chatting and maintaining social media profiles.

For the slum community respondents, television was the most popular medium and was described as their libangan, which translates to English as 'leisurely activity', but locally also means 'something with which to pass the time', implying that television viewing is a practice that keeps a person occupied in the absence of urgent tasks or responsibilities. Many women in the slum community were under- employed or jobless, and would stay at home most days keeping occupied with television entertainment, occasionally watching with their neighbours.

For the women with whom I spent time watching television in their homes, television viewing took on a melodramatic character, which in Tufte's words, is 'based largely on an emotional relation with their audience enabling the articulation of a broad variety of feelings and identities' (2003: 4). Given that the national newscasts privilege images proximal to people's lifeworlds, television viewers often relate to news and other factual genres in the same melodramatic manner that they do with soap opera. They engage in social recognition, seeing themselves as the could-have-been-me of news reports, experiencing others' difficulties as only the more graphic or dramatic versions of their own.

If there is any sense of pleasure or ontological security fostered in the television practices of low-income communities, it is a sense of gratitude that is expressed upon the social comparison between their personal situation and their more news- worthy others. As 42year-old respondent Amparo reflected upon seeing a report on poor children in the news:

You know, I only gain inner strength (lumalakas ang loob). I say to myself, I will not let that happen to my family. I remember I am so blessed by God that our family is complete, that we have food to eat.

In contrast, the middle-class respondents did not experience television as a constant flow that serves as the reliable backdrop to the everyday, but as individual programmes, particularly foreign television shows. Middle-class respondents were hard-pressed to name the titles of popular local soap operas and demonstrated their distance from local popular culture. Some deployed discourses of product- ivity to say that television viewing is only for 'lazing around during weekends', while some more self-consciously performed their sophistication and taste for what they describe as higher quality foreign programming. 'I don't really watch local' was a phrase often heard from middle-class 
respondents, as a reflexive performance of middle-classness that de-values the 'trashy' and 'shrill' television programming that is oriented to mass and low-income markets.

One respondent, businesswoman Tamara, claims she has 'no time' for Filipino television in this way:

I get a headache whenever I watch local. Newscasters top each other by speaking louder or shrieking at a higher pitch. Even the graphics are loud and make you dizzy. We're not children here, we don't need talking down to.

This quotation illustrates how the classed morality of respectability, which operates on surveilling and de-valuing forms and people deemed excessive (Skeggs and Wood, 2011), shapes the middle-class reception of mass-oriented Filipino televi- sion. This judgment is also very much present in much elite cultural criticism about Filipino popular culture, which assumes that Filipino television is dumbed down for their low-income, less educated target audience. Media critics such as De Jesus (2011) disparage both Filipino television and their very audiences for this symbiosis, whereby television targets the 'audience at the bottom of the pyramid [ . . ] the least common denominator. It is like feeding them one kind of food, the easiest to digest, yes, baby food, to adults with teeth.' This middle-class consumption practice of switching off from Filipino television is problematic when it leads to a lack of familiarity and understanding of local and everyday issues concerning the Filipino poor. I argue that this act of switching off from Filipino television while being drawn to global television is a form of social denial insofar as it, first, elides the possibilities of encountering news images that can put forth moral claims to act on other people's poor conditions, and second, even de-values and delegitimizes the poor subjects who appear on media screens as excesses or disturbances with whom the more wealthy and privileged in society have no attention and responsibility for.

\section{Contesting representations of Typhoon Haiyan}

Typhoon Haiyan is the strongest recorded typhoon in history to ever make landfall when it smashed through communities across multiple islands in central Philippines. The disaster caused over 8,000 casualties, thousands recorded as still missing with bodies yet to be found and identified, four million forced from their homes, and millions pushed further into poverty with the destruction of livelihood. The scale was given visibility by global media organizations and drew the attention and support of multilateral and humanitarian agencies, other governments, and ordinary people from other parts of the world sending donations.

Global media's mode of witnessing was to testify to 'suffering at its worst' (Orgad, 2008: 21) through high-emotion and multimodal narrative, as best exemplified by Anderson Cooper's impassioned live reporting for $\mathrm{CNN}$ : 
It is a miserable, miserable situation here and it does not seem to be getting better day by day. We are entering the fifth day since the storm hit here in Tacloban. And I can just tell you, we are in the airport now, there are hundreds of people here staying all night - they have nowhere else to go...If you walk three blocks here, you can see people sleeping in makeshift huts in the rain, sitting close to the bodies of their loved ones nobody has picked up, because there's nobody here to pick them up .... It is a very desperate situation, among the most desperate I have seen in covering disasters in the last couple of years ...

This representation of suffering at its worst in global media was successful in drawing worldwide attention and help with humanitarian fundraising. My inter- view with an official of the UK's Disasters Emergency Committee reported that their Haiyan appeal was among their most successful fundraising initiatives for a natural disaster. The appeal used the classic iconography of the ideal victim (Moeller, 2002), in this case, a single Filipino child injured in the face and drenched by rain.

Within the Philippines, however, our studies observed how media representa- tions of the country at its worst conditions of suffering were received with ambiva- lence and anxiety - particularly by our middle-class participants. Borrowing from the historian Aguilar (1996: 103), I would say that the global circulation of images of a devastated Philippines brought about a sense of 'transnational shame' for many middle-class people, a feeling of humiliation upon hearing accounts that besmirch 'the good name of the Filipino'. For Aguilar, this is very much historic- ally rooted in Filipino elites' 'profound sensitivity to the shaming of the nation- cum-race and in an insecurity borne out of [their] internalization of such racism' from their colonial overlords (p. 104).

In the wake of Anderson Cooper's report for CNN, middle-class cultural critics for instance such as Claudio (2013) reacted to the sting of global news reports, with a palpable sense of 'transnational shame' in the expose of atrocity by western parachute journalists:

I have watched this tale unfold over $\mathrm{CNN}$ and other news media. As the days have become frustrating, our hearts and minds want to stop the onslaught of these painful reports ... Easy to find fault in incompetent and corrupt government, especially in an underdeveloped country where, indeed, there is much corruption and much incompetence ... At this point, I would rather reach out to the exhausted aid workers in government, who certainly will not be strengthened by CNN's bashing of THEIR government; of OUR government. At this point, I would prefer a thousand parachuting pep squads bringing water food and hoorays rather than another international journalist who does not have the wisdom to see the larger spiritual truths that we need now and make those truths the ethical center from which they make news reports.

Indeed, in the wake of Haiyan, the lay moralities embraced and enacted by the middleclass, as instantiated through particular memes in social media, was of performative resilience. Middle-class audiences' lay moralities of suffering involved challenging photojournalist images of suffering and instead circulating positive emotions of hope and gratitude while calling for national unity and solidarity. In these memes, photorealistic 
images of suffering are erased from the picture; nationalistic and - sometimes - religious iconography are instead used to accompany inspirational and uplifting messages that call for hope and resilience rather than despair or political criticism. These images are striking not for their uniqueness in global visual cultures - playful animation is part of broader global trends in political memes in western contexts (Penney, 2014) - but for their distinctiveness in the communicative ecology following Typhoon Haiyan. In Figure 1, the image of the bamboo tree with leaves in the flag colours of the Philippines represents the resilient Filipino, who - in popular folklore - is said to be pliant like a bamboo, bending gracefully in the winds of adversity and resilient in recovery. 


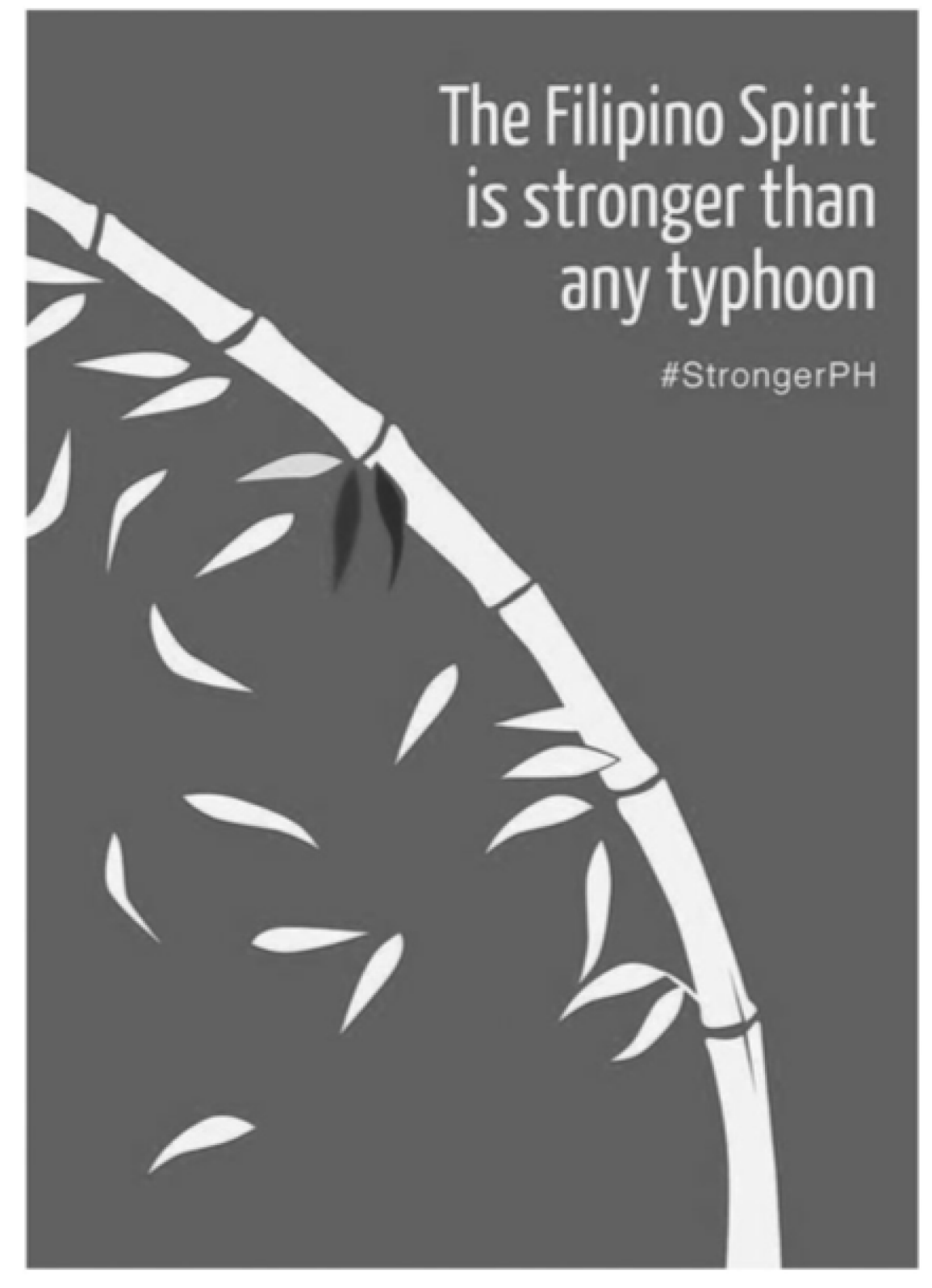

Figure 1. Photo taken from Philippine Red Cross Facebook page (https://www.facebook.com/ phredcross/photos/a.762557883769623.1073741842.220779007947516/762578767100868/ ?type $1 / 43 \&$ theater).

The image was widely circulated via social media, along with similar themed memes that recuperate Filipinos' so-called resilience in the face of disaster.

Another example of the use of comfort zone communication in ordinary people's representations of suffering was the campaign \#PHThankYou, which was spear- headed by middle-class civil society leaders and eventually adopted by the state as an official tourism campaign. This campaign encouraged citizen participation in producing memes 
whose objective was to express gratitude towards foreign donors and volunteers.

Ordinary people used the hashtag \#PHThankYou to accompany pictures of donations such as relief goods while tagging their foreign friends who sent the donation, just as they used it when thanking celebrities who visited Tacloban, such as Justin Bieber and David Beckham. The images from the official state-sponsored campaign showed redevelopment, smiling workers, and costumed ambassadors of a country saying 'thank you' (see Figure 2), never minding the enduring atrocity of Haiyan, where over 15,000 still lived in tents 9 months after Haiyan hit.

It is in this light that I argue that middle-class lay moralities involved social denial. In calling for national unity, rejecting the painful reports of international journalists, and sanitizing suffering in social media campaigns organized around performative resilience, middle-class lay moralities attempt to dim the shock of disaster and manage the collective anxiety of the persistent image of the Philippines as a suffering, underdeveloped nation in the eyes of global community

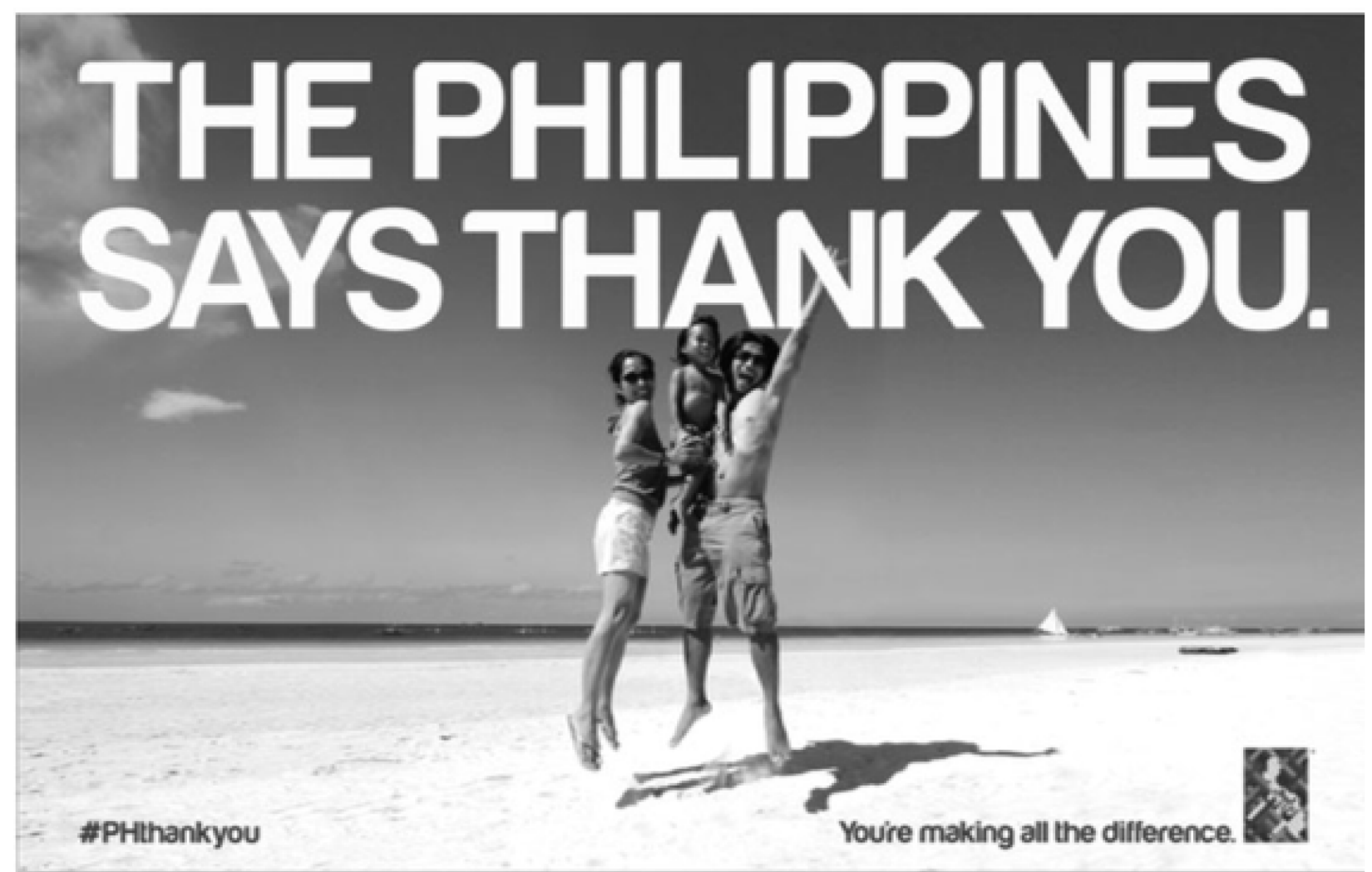

Figure 2. Photo taken from Official Gazette of Philippine Government (http://www.gov.ph/ 2014/02/08/the-philippines-says-thank-you-to-the-world/).

- an image that the middle-class has valiantly fought against through most of the nation's (post)colonial history (Aguilar, 1996). These contrasting imaginaries of Haiyan as suffering at its worst and suffering with positive images of united and patriotic survivors 
(circulating in middle-class social media, adopted in official state discourse) are of course negotiated by disaster-affected communities themselves, who - as became evident during the interviews - came to critically reflect upon stories that claim to represent them.

One of the striking findings is the scepticism that low-income disaster-affected people have toward news reports of donations and fundraising. Unlike middle-class participants who are quick to express gratitude toward promises of foreign aid, they complain about the lack of aid and suggest corruption in relief efforts. Philip, a 50-year-old father of 10 living in a UNICEF-donated tent, claims

[w]e feel sceptical about [those news reports] because sometimes...especially with government, [they] would say, 'I delivered relief goods'. But we don't actually receive them. [The delivery man] tells us they delivered corned beef [to the local government], but what we end up receiving are sardines.

Many of the low-income participants struggle to get by, with very limited opportunities for livelihood. As a fisherman living by the seashore, Philip was relocated to a tent city 45 minutes away of Tacloban City. This displacement resulted in instability in job prospects, as he had to retrain himself in carpentry work. With a wife who is unemployed, and 10 children to sustain, Philip is grateful and dependent on feeding programmes and relief goods from aid agencies, yet critical about the quality of aid they actually receive. Television images of relief goods, shelter kits, school supplies, and promises of cash donations from foreign governments are treated as indexical and proof of global care and attention. However, as we see in Philip's statement above, there is a disconnect between indexical media and his actual experience of aid, fostering feelings of disappointment and resentment. Curiously, Philip - like all of our low-income participants - is unfamiliar with the positive images of the \#PHThankYou campaign. The lay moralities around their reception of Haiyan in news media centre around a concern for media to continue providing visibility to the plight of the most disenfranchised from the disaster.

\section{Prayer as solidarity for agentic distant sufferers}

One of the case studies was on the reception of the distant suffering caused by the May 2008 earthquake in Sichuan, China, which claimed 90,000 lives and destroyed over 15 million homes. Much of the reporting in the international media, including in Philippine primetime news, focused on the response as being a model of disaster relief (Danahar, 2008), where the Chinese government was praised for its swiftness and openness, and the country in general noted for its wealth and resilience of infrastructure. The only significant criticism centred on the limited access to actual disaster zones granted to foreign journalists. Three weeks after the earthquake hit, I conducted interviews with respondents in both middle-class and low-income communities to learn whether they had knowledge of the disaster as well as to learn about their responses to selected news clips from Philippine news that reported on the emergency and relief efforts. 
I found that middle-class and low-income respondents all had prior knowledge of the disaster, having seen reports of the event in television or read articles in online portals. Across all groups, there were expressions of sadness ('I felt sorry for them'/'Sometimes I don't know why God allows these things to happen'). These tender-hearted discourses of compassion (Ho"ijer, 2004) were directed to aggregates rather than particular victims, and I suspect that this is a function of the flat reporting of the disaster that was often brief and not multimodal. In other words, the reports often failed to give name and give voice to victims. But while sorrow was expressed for the Chinese people in general, my respondents across classes also articulated rational responses to news images of the Chinese disaster, which involved critical assessment of the gravity of the disaster and an evaluation of the authenticity of its victims in reference to the Filipino context. One conver- sation in a group interview in a slum community went like this:

Lito: Their buildings are sturdy and strong anyway. Compared to ours, which are dilapidated already.

Kiko: Yes. The materials that they use are superior for sure. You know, they can withstand the force of earthquakes. Don't they have the Great Wall [of China]?

Even though the images from the newscast featured buildings reduced to rubble, they asserted that Chinese entrepreneurship and ingenuity would enable them to rebuild and recover quickly. These responses were informed by their knowledge of Chinese people in Philippine society, where they are known for their business acumen and high economic and political status. Their assumption was that, just like the Filipino-Chinese, people in Sichuan possessed enough material resources to help themselves. In other words, this judgment of Chinese sufferers as having more agency than sufferers in the Filipino context served to justify their relative lack of interest in the unfolding story and their hesitation to send any donation for the disaster-affected communities.

However, one form of action articulated across social classes was prayer. Among Christian respondents, prayer was justified as a legitimate form of action for spectators of distant suffering. Prayer here involves recognition of people's shared humanity with distant others by virtue of being God's creation, while at the same time acknowledging their difference. Praying for suffering others involves elements of tender-hearted compassion (Ho "ijer, 2004) as it expresses sorrow for other people's burdens, but at the same time draws into conversation a third actor who could respond on their behalf (e.g. 'God, please lift their burden'/'May they turn to you and draw strength'). While prayer is usually studied as an individual's coping mechanism in the face of tragedy (Cornelio, 2015), the function of prayer in this context is better explained as an expression of solidarity with distant sufferers who are similarly dependent on divine intervention for their safety and survival. Following widespread Christian beliefs of Christ's image being most evident in encounters with the miserable, it is not surprising that the encounter of distant sufferers in the Filipino news involves reflections about suffering as a shared 
affliction that can engender solidarity with distant others and facilitate a spiritual connection with the divine.

\section{Conclusion}

This article presented diverse lay moralities to mediated suffering from people whose relationship with suffering is often dangerously proximal or deeply personal rather than unfathomably distant. Among middle-class Filipinos, this encourages lay moralities premised on social denial in order to manage the anxiety and insecurity of daily encounters with sufferers - perceived to be over-represented and excessive both within and without the boundaries of media screens. Active avoidance of Filipino news displaying poverty, criticizing media practices of representing sufferers at their worst and circulating positive imagery of performative resilience in social media are strategies of blocking moral responsibility, not dissimilar from middle-class audiences in zones of safety who turn away from images of atrocity (Seu, 2003). The Filipino middle-class endure the 'transnational shame' (Aguilar, 1996) of living in a long-suffering nation, felt most deeply from the sting of global media's indignation to Haiyan's catastrophe, yet there is strong desire to connect to, rather than detach from a global public. This is seen in middle-class' high interest in international politics and global popular culture, and expressions of solidarity for sufferers in other parts of the world, which can be interpreted as acts of instrumental cosmopolitanism (Ong, 2009), where compassion for distant sufferers becomes a more convenient and self-serving emotional expression than concern for proximal others. Middle-class audiences' lay moralities of denial to local suffering and engagement with distant suffering is material for further critical reflection about the tenuous viability of cosmopolitan moral identities where embrace of distant others may come at the expense of care for neighbours.

For low-income Filipinos living in everyday poverty as well as ordinary contexts of disaster in the wake of Haiyan, what we discover from their media reception is an intense emotional connection to other people's stories of suffering. Their media practices challenge assumptions that greater and repeated exposure to images of suffering lead to 'desensitization' and 'indifference' (Cohen, 2001: 188-191), or that poor and marginalized communities seek only escape to fantasy worlds of opulence from their media. Instead, they experience mediated suffering as extensions of their own personal suffering, and find from the news symbolic resources by which to understand and cope with their own difficulties. They feel fortunate about their own lives in comparison with others', and rediscover hope and resilience in their everyday endurance of poverty, reflecting an engagement with television news not dissimilar from engagement with melodrama (Tufte, 2003). This finding, however, prompts deeper normative reflection whether the use of television - as a coping mechanism to secure ontological security within the home - is morally desirable, especially when the content is factual news about distant suffering, and if said audiences belong to marginalized groups. For media ethics scholars, it is important to consider whether the moral obligation of responsibility for 
distant others (Silverstone, 2007) is variably distributed across social groups, or is only a moral expectation for a privileged few.

Ethnographic interviews with disaster-affected communities from Typhoon Haiyan also revealed that low-income people can engage with images very critic- ally, and can heighten feelings of exclusion and resentment when media narratives disconnect with their own personal experience. This was most evident in the psychic injury of experiencing disaster relief goods as phantom presents authenticated by media as officially received by national institutions - but never personally seen, touched or tasted. The exploration of sentiments of affected peoples in relation to their own representation in global and local media, I argue, is a crucial element currently missing in most audience and textual work on mediated suffering, where judgments on good practice are either imposed by the researcher as textual analyst or drawn from patterns of their impact on audiences as potential donors. Indeed, judgments of the ethical potential of media productions must also consider the voice of the injured subject (Madianou, 2013) as it reveals lay moralities of harm or appreciation that could not be extracted from analyses of texts alone.

This partial mapping of lay moralities in witnessing distant and proximal suffering encourages for a more sociological analysis of the ways in which class - but also religion, gender, age - provides audiences with resources for judgment to speak out and take responsibility for vulnerable others in their everyday encounters with the moral invitations that circulate in our diverse media environment.

Declaration of conflicting interest

The author(s) declared no potential conflicts of interest with respect to the research, author- ship, and/or publication of this article.

Funding

The author(s) disclosed receipt of the following financial support for the research, authorship, and/or publication of this article: A section of the paper draws from a project funded by a UK Economic and Social Research Council Urgency Grant for the Humanitarian Technologies Project (ES/M001288/1), http://www.esrc.ac.uk/myesrc/grants/ES.M001288.1/ read.

\section{References}

Aguilar FV (1996) The dialectics of transnational shame and national identity. Philippine Sociological Review 44(1-4): 101-136.

Ashuri T and Pinchevski A (2009) Witnessing as a field. In: Frosh P and Pinchevski A (eds) Media Witnessing. London: Palgrave, pp. 133-157.

Bankoff G (2003) Cultures of Disaster. London: Taylor \& Francis. 
Boltanski L (1999) Distant Suffering. Cambridge: Cambridge University Press.

Chouliaraki L (2006) The Spectatorship of Suffering. London: SAGE.

Chouliaraki L (2012) Re-mediation, inter-mediation, trans-mediation. Journalism Studies 14(2): 267-283.

Claudio S (2013, 15 November) Ethics for parachuters. . Er, journalists. GMA News Online. Available at: http://www.gmanetwork.com/news/story/335601/opinion/ethics-for-parachuters-erjournalists (accessed 6 January 2015).

Cohen S (2001) States of Denial. London: Polity.

Cooper A (2013, 12 November) The "Miserable" situation in Tacloban, Philippines. CNN News Online. Available at: https://www.youtube.com/watch?v=vfkYYPSiHv4 (accessed 6 January 2015).

Cornelio J (2015) Filipino Catholic students and prayer as Conversation with God. In Giordan, G. \& Woodhead, L. A (eds) Sociology of Prayer. London: Ashgate.

Couldry N, Livingstone S and Markham T (2007) Media Consumption and Public Engagement. London: Palgrave.

Danahar P (2008, 19 May) Burma and China: Tale of two disasters. BBC News Online. Available at: http://news.bbc.co.uk/1/hi/world/asia-paciEc/7407927.stm (accessed 6 January 2015).

Dayan D (2007) On morality, distance and the other. International Journal of Communication 1: $113-122$.

De Jesus MQ (2011, 26 April) TV, Willing Willie, the public sphere. In: Rex Crisostomo's Blog. Available at: http://rexcrisostomo.blogspot.com/2011/04/tv-willing-willie-public-sphere.html (accessed 6 January 2015).

Heintz M (2009) Introduction. In: Heintz M (ed.) The Anthropology of Moralities. New York, NY: Berghahn Books, pp. 1-19.

Hoijer B (2004) The discourse of global compassion. Media Culture \& Society 26(4): 513-531. 
Kinnick KN, Krugman DM and Cameron GT (1996) Compassion fatigue. Journalism \& Mass Communication Quarterly 73(3): 687-707.

Madianou M (2013) Ethics of mediation and the voice of the injured subject. In: Couldry N,

Madianou M and Pinchevski A (eds) Ethics of Media. London: Palgrave, pp. 179-197. Moeller S (2002) A hierarchy of innocence. International Journal of Press/Politics 7(1): 36-56.

Nussbaum M (2001) Upheavals of Thought. Cambridge: Cambridge University Press.

Ong JC (2009) The cosmopolitan continuum. Media, Culture \& Society 31(3): 449-466.

Ong JC (2014a) “Witnessing', or “"mediating”' distant suffering? Television \& New Media 15(3): 179-196.

Ong JC (2014b) Communications in disaster recovery. Paper presented at Philippine Sociological Society Annual Conference, General Santos City, Philippines.

Ong JC (2015) The Poverty of Television. London: Anthem.

Orgad S (2008) Agency and distance in the representation of suffering. Paper presented at the ICA Annual Conference, Montreal, Canada.

Penney J (2014) Social media and symbolic action. Journal of Computer-Mediated Communication 20(1): 52-66.

Romualdez E (1999) Interview: Eugenio Gabriel Lopez III. In: Coronel S (ed.) From Loren to Marimar. Quezon City: Philippine Center for Investigative Journalism, pp. 54-57. Sainath P (2009, 20 April) No issues. The Hindu. Available at: http://www.hindu.com/2009/ 04/20/stories/2009042051620800.htm (accessed 6 January 2015).

Scott M (2014) The mediation of distant suffering. Media, Culture \& Society 36(1): 3-19. Seu B (2003) Your stomach makes you feel that you don't want to know anything about it. Journal of Human Rights 2(2): 183-196.

Silverstone R (2007) Media and Morality. Cambridge: Polity. 
Skeggs B and Wood H (2011) Turning it on is a class act. Media Culture \& Society 33(6): 941951.

Tester K (2001) Compassion, Morality and the Media. Buckingham: Open University Press.

Tufte T (2003) Telenovelas, Culture and Social Change. Available at:

www.portalcomunicacion.com/catunesco/download/tufte_telenovelas.pdf (accessed 6 January 2015).

Wells K (2013) The melodrama of being a child. Visual Communication 12(3): 277-293. 